\title{
Reflections on Writing about Health and Well-Being during the COVID-19 Pandemic
}

\author{
Stacey L. Camp ${ }^{1}$ - Laura Heath-Stout ${ }^{2} \cdot$ Kimberly Wooten $^{3}$ - Jodi A. Barnes ${ }^{4}$ (D . \\ Sarah Surface-Evans ${ }^{5} \cdot$ Zada Komara $^{6}$. Alyssa R. Scott ${ }^{7}$
}

Accepted: 15 December 2021/ Published online: 7 January 2022

(C) The Author(s), under exclusive licence to Springer Science+Business Media, LLC, part of Springer Nature 2022

\section{Stacey L. Camp}

Editing this volume has been both a political and personal project for me. As a longtime sufferer of a chronic illness, I have been interested in how disparities in healthcare, be it the care an individual receives or the care an individual can afford, shape an individual's life course. Healthcare is not apolitical; a person's class, gender, citizenship, and racial status can determine the quality and amount of care they receive. As we see here in the United States, the first people who were tested for COVID-19 were not those who were vulnerable, on the frontlines of fighting the virus, and in need, but rather wealthy politicians and athletes who had the capital and power to access tests. In the middle of this pandemic, the structural factors influencing people's care seem insurmountable. How do we fix this system given the politicalization of masks, the material culture essential to preventing the spread of COVID-19?

\section{Laura Heath-Stout}

In my contribution to this special issue, I wrote about compulsory ablebodiedness among archaeologists, and as our society confronts the coronavirus pandemic, wrestling with how and when to resume our everyday lives, this idea seems especially relevant. On the one hand, the pandemic has made ablebodiedness less compulsory than usual: accommodations that disabled people have requested for years, like working from home and participating in events through videoconference, have become the norm. It has been frustrating and illuminating to see the flexibility that becomes suddenly possible once nondisabled people need it. I hope that once there is a vaccine and we can resume our old habits, we remember that people do not need to follow regimented schedules under the noses of their supervisors in order to do their work, and that deep relationships can be built and sustained at a distance.

Stacey L. Camp

campstac@msu.edu

Extended author information available on the last page of the article 
I worry, though, about the pressure to reopen businesses, organizations, and universities before there is a vaccine. How many disabled, chronically ill, and/or immune-compromised people will be forced to leave the safety of their homes in order to meet our basic economic needs? As our workplaces reopen, we are compelled to compromise our safety and wellbeing in the name of productivity and profit. This pressure falls heaviest on those who are already most marginalized, and may have life-or-death consequences for those most susceptible to severe COVID-19 due to age or health conditions. As I did in my article, I call on all who read this to remember that although we may appear nondisabled, disabled people are all around you. Wear your mask. Wash your hands. If you have the power to allow us to work from home, please do so. Be flexible. Honor our needs and keep us safe.

\section{Kimberly Wooten}

I think about the idea of ACCESS a lot, and lately, with the pandemic and America's struggle to address systemic racism and profound social inequality, I think about ACCESS every single day. Access to healthcare, to good grocery stores, to affordable home loans, to a good education for children, with safe elementary schools and where the rate of high school students attending a four-year college is an attainable reality. Sometimes there isn't the absence of access-that one has an opportunity, but can't reach for it-sometimes there simply is no opportunity to be had: a food desert or a healthcare wasteland, dangerous streets. But what I return to over and over again when I think of ACCESS is healthcare. What would have happened to my family without a job that provided the best healthcare attainable? Undoubtedly bankruptcy at best, like so many Americans, or at worst, my children growing up without their mother. Affordable healthcare is critical to equality, and in a nation struggling with a global pandemic, the lack of healthcare - preventative care, and when necessary, critical care - has been devastating. On average, Black men and women are three times more likely to die from COVID-19, a devastating statistic that kills after years of system racism, years of lack of access to what many of us take for granted. Black women are four times more susceptible to death during or shortly after childbirth, and those women's sons and daughters are twice as likely to die in infancy as a White woman's child. I think about it all the time, about who lives and dies, not just in a pandemic, but in simple day-to-day life. Universal health care saves lives, and ACCESS should not be a privilege, but a basic human right.

\section{Jodi A. Barnes}

I spent most of the shutdown in rural Arkansas, where I could draw parallels between life during the pandemic and life at the turn of the twentieth century. The university where I taught moved courses online on March 12 as the state shut down due to COVID-19. But as people left campus and returned to their home 
communities, many students had to depend on their phones for access to class materials because of limited computer and/or internet access. On April 12, tornadoes blew through the area leaving campus and the surrounding area without power for up to a week. The pandemic and the power outages highlighted the fierce inequities faced in rural areas.

Although my life is very different from the Taylor family's, I could imagine how disconnected they may have felt from other parts of the country at times. The local newspaper is a weekly and there is no investigative journalism, so most people get their news from state and national stations, like FOX and $\mathrm{CNN}$ and learn about local happenings from social media and word of mouth. This lack of local information was worrisome, as there were limited ways to find out about the number of positive cases and the availability of tests in my area. As the number of positive cases rose in my county, there were rumors that so and so was diagnosed with COVID-19, combined with a lot of false information and mask bashing. With the lack of communication from hospitals, government officials, and the emphasis on individual actions as a way to prevent the spread of infection, it made me think about health crises in the past. How did Henry Taylor learn to treat his tuberculosis? How did he choose to go to Wisconsin for care?

I lived in a town of 10,000 people. It has a Walmart, and it's a food swamp with lots of fast-food restaurants but limited healthy meal options. It is surrounded by smaller towns with the nearest cities about 90 miles away. With the power outage and COVID-19, I thought often about access to resources and what I would do if supplies stopped coming into this region. I was reminded how intimately the Taylors and the Black men and women who labored on their plantation were tied to climate and supply chains.

Similarly, the people who work in Walmart, the fast-food chains, and nursing homes are mostly Black and Latinx, along with a number of elderly white people. Both populations were at increased risks, yet like across the country, people refused to wear masks, dehumanizing the people who provide basic necessities. My nextdoor neighbor is an elderly White woman. A Black woman lives with her, going grocery shopping, buying aloe and alcohol to make hand sanitizer when Walmart was out, preparing her meals, and caring for her health. With COVID-19 impacting the elderly and nursing homes, Brenda risked her health in this care, and it is a stark reminder of inequality, as so many cannot afford this type of health care. I was reminded of the Black women who lived and worked in the kitchen in the care of the Taylor household, how did they take precautions to maintain their health?

In September 2020, my brother died of health conditions that were (probably) not related to COVID-19. I went to his memorial service and worried that I was at a super spreader event being the only person wearing a mask. It was sad to see the polarization around masks and the shared health of communities so personally. Most of the people in power in my town followed the rhetoric of the president and treated the pandemic accordingly and didn't mask up either. Yet with the death of George Floyd, Black community leaders and high school students organized a Black Lives Matter march and rally. This was the first protest in my area, which has a history of KKK terror, and everyone wore masks. At a time when the federal, state, and local 
governments were emphasizing individual self-care, this was a powerful moment of collective and shared grief that illustrates community care. I still don't know how to understand these divergent ways of understanding well-being, and I'm unsure how we will address the vast inequities the pandemic revealed, but I am grateful for the authors in this volume who offered a way to speak to these concerns through archaeology.

\section{Sarah Surface-Evans}

COVID-19 laid bare all the failures of our institutions - the injustices of capitalism, the systematic racism marginalizing entire communities, the inadequacies of our healthcare system, and rampant ableism underlying Western medical practice. As an archaeologist who has spent the last decade studying Federal Indian Boarding Schools and their numerous failures, I have spent a lot of time reflecting on failed institutions and the lasting ripples of harm they cause and the various, creative forms of resilience that people develop in response. Many of the contributors in this volume provide excellent case studies for this interplay and struggle and these conversations are more important than ever for moving forward and creating positive change in the wake of the COVID-19 pandemic. When I reflect on the last four months, March through July 2020, several themes emerge from my own perspective as a queer, disabled, and chronically ill academic.

In the beginnings of the pandemic in the United States, Michigan was among the first states to be affected. The Governor of Michigan issued a mandatory "stay at home" order on March 23rd that lasted until June 12th, 2020. There was a sudden, large-scale disruption of the normal routines of life and the day-to-day cadence of capitalism. After the initial panic passed, I was struck by the atemporality of existence. During this absence of the usual routines, time in the capitalist sense, became meaningless. People began to speak of "COVID-time." I learned from this disruption, just how much our economy and society structure our perception of time. This experience jarred me so much that I will now question my assumptions about the sensibilities of time when interpreting the past. Now I mourn the loss of the temporal space that was created during this temporary pause as we collectively rush back to a "normal" that does not accommodate crip-time.

COVID-19 also exposed the rampant ableism in our society. I will share just a few of my personal experiences here. As phased re-opening began in June 2020, I found myself in a strange liminal space, where people around me were returning to life without me. My status as chronically ill and disabled is largely invisible to others. My friends, family, and colleagues were comfortable with the level of risk associated with socializing, leaving me on the sidelines, isolated. With an immunocompromised health status and decades of negative experiences with Western medicine, I had little faith in the medical system being able or even willing to provide me care if I should become ill with COVID-19. My fellow "spoonies" and I traded alarming stories about the disproportionately high death rate among the Black, disabled, chronically ill, and transgender communities due to COVID-19. These communities often share intersectionalities and disturbingly, are also the people most likely to be 
denied critical care when hospitals were overwhelmed with COVID-19 patients. In addition, unfounded claims of Hydroxychloroquine as a cure for COVID-19 caused a critical shortage for those of us who need this drug to maintain our wellness. This forced me to reduce my daily dosage for months. Other spoonies I know had to make even more dire decisions regarding their health due to this shortage.

Perhaps most galling to the disability community is the appropriation and misuse of Americans with Disabilities Act (ADA) status by those who chose not to wear masks. I witnessed protests at the Michigan capital firsthand, as masks were politicized and weaponized. The anti-mask crowd put everyone at risk, especially the vulnerable ill and disabled communities. For me, these experiences reinforce the need for archaeologists to include critical perspectives in their interpretations that do not normalize ableism. Perhaps a small silver lining is that for the first time some ablebodied individuals experienced a newfound appreciation for living in a society that does not prioritize their health or wellbeing over profit and preserving the economy. Ever the optimist, I am hopeful that this insight will translate into positive change for the future.

Lastly, the impacts of COVID-19 on mental health are numerous and far reaching during this collective period of mourning and anxiety. Mental healthcare in the United States is the most underfunded and undervalued aspect of our health system. But mental health impacts many aspects of well-being, and long-term stress has a very real impact on the body. Disturbing news about the increased rates of overdoses and drug and alcohol abuse during the pandemic, speaks to the unhealthy coping mechanisms in our society when mental healthcare is not available or normalized. Additionally, prolonged stress can create ripple effects on well-being, causing intergenerational trauma. Many of us are mourning lost loved ones during this time and are unable to seek the comfort of family and friends. During the pandemic, my family struggled with the news that my father-in-law was diagnosed with cancer on the same day the lockdown started in Michigan. His health rapidly deteriorated and we were unable to visit him until just before he passed away on July 25th, 2020. While I process my own grief, I am also concerned about my children, who are going through so many incredible stressors at once. I feel incredibly privileged and fortunate that we have access to mental healthcare and that I had the ability to take a period of leave from work to focus on the mental health of myself and my family. However, as a society, we need to de-stigmatize mental healthcare and provide more support for individuals in crisis.

\section{Zada Komara}

My father died during the pandemic. Not from COVID-19 (probably) but from a series of strokes that kept him in the hospital dying for weeks without a single visitor. My mother, a former hippie charmed by New Age medicine, emailed me an article while he was dying with a subject line that said "interesting." The article claimed that COVID-19 is not actually a contagion and that the real pandemic is $5 \mathrm{G}$ wireless which "activates" the virus in our bodies and the article suggested we should all just contract it for herd immunity. This is some real damn nonsense but I think I 
understand the appeal. I don't think my mother truly believes, but what if, just what if, it were true and she could have safely held my father's hand goodbye? I thought about pseudoscience a lot while Dad was dying and I was writing this article. Patent medicines seem ludicrous to us now - snake oil foisted on a medically illiterate populace who foolishly wanted to believe - but context is important. Complementary and Alternative Medicine (CAM) and naturopathy now offer some of the same lure: systems of consumer-driven medicine that put the unwell in charge outside of the surveillance and dominance of scientific medicine. COVID-19 has exposed the radical inequities of our healthcare system and our society, notably racism, sexism, and classism. Is it any wonder that the unwell and unsure exercise agency through other systems of practice and meaning? Colloidal silver and cow urine are the new nervine tonics in our modern crisis. Writing this article during the pandemic became a sort of meditation, a way to think through the importance and nuance of medical literacy and ontological empathy. I see my mother in these old bottles of tonic for "weak women" and also see myself as I struggle to make sense of healthcare, grief, and healing. This article has fittingly helped me process. It has itself been a purgative.

\section{Alyssa R. Scott}

The process of doing research on TB during the COVID-19 pandemic has been emotionally draining. Although it is easy to draw comparisons between covid and TB (they both have respiratory symptoms, isolation, greater use of outdoor spaces), one thing that has been particularly difficult for me is the fear that people will misinterpret what I have, and apply it to the covid pandemic when the two diseases have critical differences. For example, institutionalization in a sanatorium is not the same as confinement at home during the lockdown. Only a small segment of people with TB went to a sanatorium. Additionally, covid is an emerging disease which spreads rapidly and is full of unknowns, while tuberculosis was an ancient endemic disease and for many people in the past, more akin to a chronic illness. At least one important thing that has come out of the pandemic is greater public recognition of the role between social inequality, health, and the environment. Prior to this project, I frequently encountered friends, students, academics, and members of the public who had never fully considered the idea that the inequality could have a real impact on infectious disease or a person's health. Additionally, people spoke about environmental issues such as climate change and social issues as two separate and competing problems, rather than an interconnected situation in which people who are subject to discrimination are also the most exposed to natural disasters, toxicity in the environment, and other associated health risks. Additionally, the pandemic has highlighted the fact that understanding social issues is imperative, since scientific advancements will only help if they are accessible to people and if people accept them. I hope that people will not forget the connection between social issues, material culture, the past, and the environment. 


\section{Declarations}

Financial Interests The authors have no relevant financial or non-financial interests to disclose. All authors certify that they have no affiliations with or involvement in any organization or entity with any financial interest or non-financial interest in the subject matter or materials discussed in this manuscript.

The authors have no financial or proprietary interests in any material discussed in this article.

Competing Interests The authors have no competing interests to declare that are relevant to the content of this article.

Publisher's Note Springer Nature remains neutral with regard to jurisdictional claims in published maps and institutional affiliations.

\section{Authors and Affiliations}

\section{Stacey L. Camp ${ }^{1} \cdot$ Laura Heath-Stout $^{2} \cdot$ Kimberly Wooten $^{3}$. Jodi A. Barnes ${ }^{4}$ (i) . Sarah Surface-Evans ${ }^{5} \cdot$ Zada Komara $^{6} \cdot$ Alyssa R. Scott $^{7}$}

Laura Heath-Stout

laura.heathstout@umb.edu

Kimberly Wooten

vintage_mama@hotmail.com

Jodi A. Barnes

barnesj@dnr.sc.gov

Sarah Surface-Evans

surfa1s1@cmich.edu

Zada Komara

zadakomara@uky.edu

Alyssa R. Scott

Alyssa_scott@berkeley.edu

1 Department of Anthropology, Michigan State University, East Lansing, MI, USA

2 Department of Anthropology, University of Massachusetts Boston, 100 William T. Morrissey Blvd., Boston, MA 02125, USA

3 California Department of Transportation's Cultural Studies Office in Sacramento, 1446 Jackson Gate Road, Jackson, CA 95642, USA

4 South Carolina Department of Natural Resources, Heritage Trust, 918 Duke Street, Georgetown, SC 29440, USA

5 Department of Sociology, Anthropology, and Social Work, Central Michigan University, 138 Anspach Hall, Mount Pleasant, MI 48859, USA

6 Lewis Honors College, University of Kentucky, 447 N. Martin Luther King Blvd., Lexington, KY 40508, USA

7 Department of Anthropology, University of California Berkeley, 232 Kroeber Hall, Berkeley, CA 94720, USA 